\title{
TRAUMATIC DIAPHRAGMATIC HERNIA IN AN INFANT
}

Vaidyam Chakravarthi ${ }^{1}$, Harita $\mathrm{M}^{2}$, Yoga Nagendhar ${ }^{3}$

\section{HOW TO CITE THIS ARTICLE:}

Vaidyam Chakravarthi, Harita M, Yoga Nagendhar. "Traumatic Diaphragmatic Hernia in an Infant". Journal of Evolution of Medical and Dental Sciences 2014; Vol. 3, Issue 06, February 10; Page: 1463-1465,

DOI: $10.14260 /$ jemds/2014/2008

ABSTRACT: Traumatic diaphragmatic ruptures are relatively rare, but are increasingly being reported due to their commonness in motor vehicle accidents. This case report is of a one-year old female child similarly injured, who presented very early after the insult, with none of the abdominal symptoms or signs that usually point to this diagnosis. This case underscores the fact that clinical scenario in pediatric patients does not always correlate with the degree of severity of injury and also that CT scan of chest is superior to radiographs and ultrasonography in detecting early diaphragmatic rupture.

KEYWORDS: Pediatric trauma, infant trauma, diaphragm rupture, diaphragmatic hernia

CASE REPORT: A 1-year old female child was admitted to our hospital as a result of motor vehicle accident, where the wheel of a van had passed over the child's thorax. On physical examination, the child was disoriented, with gross edema all over the face, no eye opening, profuse epistaxis and bleeding from left ear. There were multiple bruises all over the forehead and right cheek and a swelling (probable hematoma) over the left infra-auricular area and the back of neck. The upper part of the thorax showed only an erythematous band at the base of the neck. Rest of systemic examination was normal. Initial resuscitation was done and after the patient's vital signs were stable, all standard emergency diagnostic procedures were performed. CT scan brain was normal; abdominal USG was normal, pelvic radiograph was normal. Chest radiograph showed tip of nasogastric catheter upturned and lying in the thoracic stomach, mediastinal shift to the right, obliteration of the left costophrenic angle, elevation of left hemidiaphragm, and multiple contusions in the left lung mid-zone area. Thoracic CT scan (Figures 1, 2, 3) showed left hemithorax replaced by multiple air and fluid filled bowel loops, stomach displacing the mediastinum towards the right, and superior migration of the collapsed lung. There is superior migration of the spleen and free fluid in the left pleural space with indistinct left diaphragmatic crux, all suggestive of left diaphragmatic rupture. Laparotomy was done under general anesthesia, ICD was placed and diaphragm repaired. After an uneventful post-operative period of one week, the child was discharged home.

DISCUSSION: The different mechanisms leading to a diaphragm rupture after a blunt trauma are avulsion of the attachments of the diaphragm or shearing of the stretched membrane after right or left lateral impact to the chest wall, rib fracture fragments directly penetrating the diaphragm and a sudden increase in the intraabdominal pressure throughout the abdomen with the relatively weak, unprotected left diaphragmatic tearing from the force. The right hemidiaphragm is also protected from abdominal impact by the energy- absorbing liver1, 2, 3 .

The left diaphragm is injured in $50 \%$ to $88 \%$ of patients who have blunt diaphragmatic rupture, whereas right-sided injuries are less frequent and occur in $12 \%$ to $40 \%$ of cases. Children manifest an approximately even rate of right- and left-sided injuries that may be due to the increased mobility of the liver that affords less protection to the right hemidiaphragm than in adults4,5. The 
higher frequency of left-sided injury has been attributed to an area of congenital postertolateral weakness 5,6 .

There are three described phases of diaphragmatic rupture ${ }^{7}$. The first acute phase is at the time of injury of the diaphragm, the second delayed phase is because of transient herniation of the viscera accounting for absence or intermittent non-specific symptoms and the third obstruction phase due to complication of a long-standing herniation, manifesting as obstruction and strangulation.

Symptoms may be non-specific and include dyspnea, chest pain, shoulder pain and cyanosis. Typically symptoms are secondary to visceral herniation through the diaphragm defect. Bowel sounds over the hemithorax are suggestive, although other physical findings, such as decreased or absent breath sounds, contralateral mediastinal shift, abdominal tenderness, and guarding, are nonspecific and are obscured by signs of other more obvious life-threatening injuries. Consequently, a high index of suspicion is required.

Associated injuries are common in traumatic diaphragmatic ruptures $(52-100 \%$ of the patients) 3 . The most commonly damaged intraabdominal organs are liver (disrupted in 93\% of patients with right-sided injury) and spleen (in $24 \%$ of those with left-sided injury). In our patient, splenic hematoma and left lung contusion were observed intra-operatively. Other commonly associated abdominal injuries include pelvic and renal injuries and associated intrathoracic injuries include hemopneumothorax and rib fractures.

The chest radiography as initial screening of diaphragmatic rupture has a relatively low sensitivity for diagnosis, which was reported as diagnostic in $46 \%$ of patients with left sided rupture and suspiciously rupture in another $18 \% 4$. The preferred diagnostic method should be CT in blunt traumas. Conventional CT has a variable sensitivity of $14-61 \%$ and a specificity of $76-99 \%$ in the diagnosis of diaphragmatic rupture ${ }^{1}$. Helical CT is a more accurate diagnostic method in the detection of diaphragmatic rupture, with a sensitivity of $71-84 \%$ and a specificity of $77-100 \%{ }^{6}$.

Open surgical repair has been the traditional method of treating blunt diaphragmatic ruptures. Surgical approach is most often abdominal, but may require a thoracic approach, especially with a right-sided injury.

CONCLUSION: Because of potentially devastating delayed complications, early diagnosis of diaphragmatic injuries should be an important goal in the care of trauma patients. Despite the increasing availability of MR imaging and advancing videoscopic techniques, routine chest radiography and helical thoraco-abdominal CT usually lead to the correct diagnosis and are also helpful in the follow-up of these patients.

\section{REFERENCES:}

1. Sivit CJ, Taylor GA, Eichelberger MR. Chest injuries in children with blunt abdominal trauma: evaluation with CT. Radiology 1989; 171: 815-8.

2. Brandt ML, Luks FI, Spigland NA, O'Ilorenzo M, Laberge J, Ouimet A. Diaphragmatic injury in children. J Trauma. 1992; 32: 298-300.

3. Adnan Narci, Tolga Alt ug Sen, Resit Koken. Asymptomatic diaphragmatic rupture with retroperitoneal opening as a result of blunt trauma. J Emerg Trauma Shock.2010 Jul-Sep; 3(3): 301. 
4. Koplewitz BZ, Ramos C, Nanson DE, et al. Traumatic diaphragmatic injuries in infants and children: imaging findings. Pediatr Radiol 2000; 30: 471-9.

5. Clint W. Sliker. Imaging of Diaphragm Injuries. Radiol Clin N Am 44 (2006) 199-211.

6. Iochum $\mathrm{S}$, Ludig $\mathrm{T}$, Walter $\mathrm{F}$, et al. Imaging of diaphragmatic injury: A Diagnostic Challenge? Radiographics 2002; 22: S103-18.

7. Grimes OF. Traumatic Injuries of the Diaphragm. Diaphragmatic Hernia. Am J Surg.1974; 128:175-81.

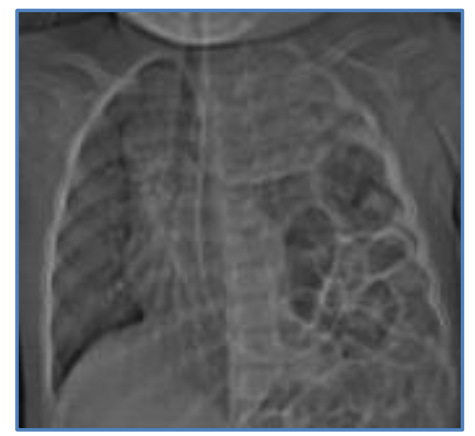

\section{Figure 1}

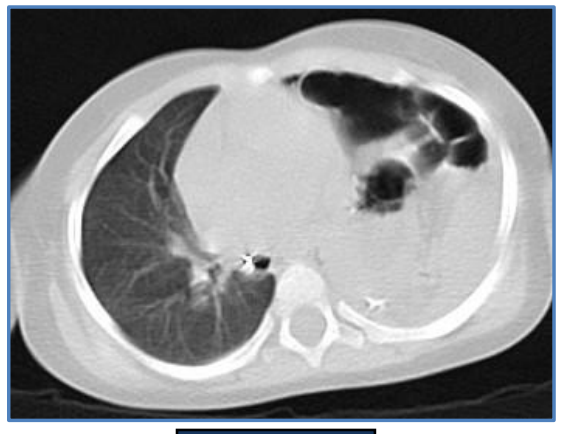

Figure 2

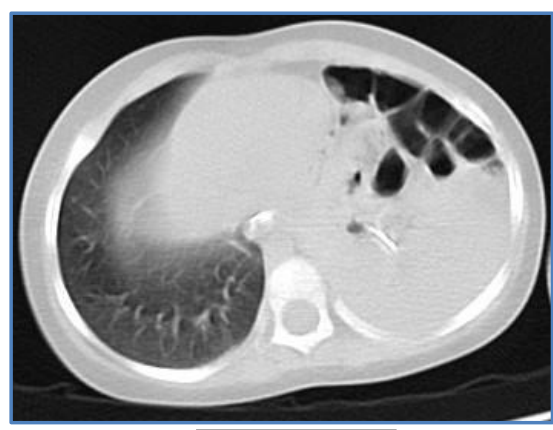

Figure 3

\section{AUTHORS:}

1. Vaidyam Chakravarthi

2. Harita M.

3. Yoga Nagendhar

\section{PARTICULARS OF CONTRIBUTORS:}

1. Consultant Pediatrician, Department of Pediatrics, SAFE Mother \& Child Hospital \& Assistant Professor, Deccan College of Medical Sciences, Hyderabad.

2. Senior Resident, Department of Pediatrics, SAFE Mother \& Child Hospital, Hyderabad.

3. Consultant Pediatric Surgeon, Department of Pediatrics, SAFE Mother \& Child Hospital, Hyderabad.

\section{NAME ADDRESS EMAIL ID OF THE CORRESPONDING AUTHOR:}

Dr. V. Chakravarthi,

SAFE Mother \& Child Hospital, \#17-1-382/P187,

Government Press Colony, Sagar Road,

Champapet. Hyderabad - 5000079.

E-mail: dr_chakravarthi@rediffmail.com

Date of Submission: $15 / 01 / 2014$.

Date of Peer Review: 16/01/2014.

Date of Acceptance: 28/01/2014.

Date of Publishing: 06/02/2014. 